\title{
Body Posture and Breathing Frequency in Newborn Mammals
}

\author{
JACOPO P. MORTOLA ${ }^{(28)}$ \\ Department of Physiology, McGill University, Montreal, Quebec, Canada H3G IY6
}

\begin{abstract}
Summary
The effects of changing body posture on breathing frequency (f) of anesthetized newborn rats, rabbits, and dogs have been studied. No significant changes were observed between horizontal postures (supine, prone, left, and right lateral). In the vertical head-down position, most of the animals did not show any significant variation of $f$. Breathing rate dropped significantly in the head-up position, and in all the animals, it was still below the horizontal value 1 min after the vertical head-up tilting. After bilateral vagotomy, no significant change with body posture occurred. In unanesthetized newborns, the $+45^{\circ}$ head-up tilting only occasionally caused a drop of $f$ and to a lesser extent than after anesthesia. By comparing these results with those reported in adults, it is concluded that the postural effects of $f$ are less evident in the newborn than in the adult. Even if a quantitative difference in the mechanical events after the change in body posture is the most likely explanation of the lower sensitivity of the newborn, other nonmechanical factors could also be involved.
\end{abstract}

\section{Speculation}

The postural effects on breathing rate of newborn rats, rabbits, and dogs are less evident than in the corresponding adults. The quantitative difference in the mechanical events after the postural change is the most likely explanation, but less vagal input or reflex elaboration of the vagal afferents in the newborn is also possible.

Since early observations on circulatory effects of the changes in body posture in adult mammals, respiratory manifestations have also been noticed. The vertical head-up position results in a gradual drop of breathing rate and respiratory failure in unanesthetized rabbits (24). A small degree of head-up tilting $\left(+30^{\circ}\right)$ is sufficient to cause a reduction in respiratory rate as much as $20 \%$ under light barbiturate anesthesia (10). Respiratory failure may occur, and the animal will die without resuming respiratory activity if the head-up posture is maintained for more than 3 to $5 \mathrm{~min}$ $(10,20)$. A similar tilting in anesthetized dogs induces an apnea of about $30 \mathrm{sec}$, and then breathing rate resumes and stabilizes at about $65 \%$ of the value attained in horizontal posture $(14,15)$. Longer apnea periods and more pronounced drops in breathing frequency are observed with more vertical positions $(5,14,15)$.

The primary reason for the orthostatic respiratory effects was initially believed to be cerebral ischemia secondary to a fall in blood pressure $(10,24)$, or mainly mechanical impairment of diaphragmatic movement (20). However, it was subsequently shown to be the parallelism between the head-up tilting and the Hering-Breuer inflation reflex $(10,20)$; with the head-up tilting, the weight of the abdominal viscera results in a caudal traction on the diaphragm with an increase in lung volume which inhibits respiration through the activation of pulmonary vagal afferents. On the contrary, in the head-down position, the descent of the abdominal viscera into the thorax due to gravity deflates the lung, and the parallel increase in breathing rate of anesthetized rabbits
(20) and dogs $(14,15)$ can be explained as a manifestation of the Hering-Breuer deflation reflex.

Several studies have shown the presence of vagal reflexes in newborn animals $(8,22,25)$ as well as in infants $(6,16,21)$. Inasmuch as the newborn's chest wall compliance is higher than in adults $(1,9)$, the displacement of its abdominal viscera with changes in body position will be relatively greater and may lead to a marked postural effect on the newborn's breathing rate. Very little data are available to anticipate any conclusions. In premature infants, a higher breathing rate in the prone position compared to the supine position has been reported (12), whereas in full-term infants no differences between postures were observed $(7,12)$.

In this study, the respiratory rate of anesthetized newborn rats, rabbits, and dogs and of unanesthetized newborn dogs and rabbits has been measured in different body postures, before and after bilateral vagotomy, as a way to assess the role of the pulmonary stretch reflexes in newborns.

\section{MATERIALS AND METHODS}

\section{ANESTHETIZED ANIMALS}

The experiments were performed on nine newborn rabbits (age, 2 to 14 days), six newborn rats (age, 13 days) and seven newborn puppies (age, 1 to 11 days). Their mean body weight was $172( \pm 55$ S.D.), $42( \pm 4.5)$, and $351(+73) \mathrm{g}$, respectively. The animals were anesthetized with sodium pentobarbital $(25 \mathrm{mg} / \mathrm{kg}$ IP) and a three-way metal tracheal cannula was inserted in the extrathoracic trachea. The inner diameters of the tracheal cannulas were about $8.5 / 10$ of the inner tracheal diameters. One arm of the cannula was left open to atmosphere; the other arm was connected to a Statham pressure transducer to record the oscillations of tracheal pressure during tidal breathing. Measurements of breathing frequency in various horizontal postures (supine, prone, right, and left lateral sides) were obtained by adequately positioning the animal on a supporting board. Each posture was maintained for at least $1 \mathrm{~min}$ for steady-state measurements. Postural changes were repeated several times according to a random sequence. Then the supine animal was secured to the board at the level of the upper and lower extremities for the tilting procedure. By manually tilting the board, breathing rate was measured in the $90^{\circ}$ head-down (-90) and in the $45^{\circ}$ and $90^{\circ}$ head-up (+45 and +90 ) positions. Measurements were then obtained after bilateral cervical vagotomy. Oral (in rats and rabbits) or rectal (in puppies) temperature was periodically checked between measurements, and was maintained between 36.5 and $38^{\circ} \mathrm{C}$ by adjusting the distance of a heating lamp from the animal.

\section{UNANESTHETIZED ANIMALS}

In two newborn puppies ( 8 and 11 days old, 432 and $466 \mathrm{~g}$ ) and nine newborn rabbits (from 1 to 14 days old, $176 \pm 48 \mathrm{~g}$ ), the effect of $+45^{\circ}$ head-up tilting was tested in the unanesthetized state. In some instances, the animals were secured to a board similarly to the anesthetized animals, and breathing rate was 
measured with a pair of magnetometer coils (17) placed on the lateral sides of the abdomen. In other cases, the animals were placed prone in a small animal body plethysmograph with a rubber collar around the neck, similar to the one previously used in this laboraory (27). In this case, breathing rate was measured from the oscillations of the pressure signal generated in the box with each breathing act. In both conditions after a short while, the animal rested quietly, and no body movement other than the respiratory movement was observable. It was indeed possible that the animals fell asleep, even though no attempts were made to define the state of arousal. After some minutes in the horizontal position, the board or the box was tilted to $+45^{\circ}$ head-up position and maintained in this position for at least $1 \mathrm{~min}$. The tilting occurred within a breath period and did not seem to provide any visable discomfort in the animal. In the circumstances when the animal moved during the tilting, it was clearly apparent from visual inspection or the tracings, and the trial was disregarded.

To observe the effect of anesthesia on the response of breathing frequency to tilting, the two puppies and six of nine rabbits were subsequently anesthetized, and the same maneuvres were repeated.

\section{ANALYSIS OF THE DATA}

The immediate effect of the $+45^{\circ}$ and $90^{\circ}$ head-up tilting was computed by measuring the interval from the moment of the tilting and the onset of the next breath. In addition, for each posture, the instantaneous breathing frequency has been calculated for 10 to 20 breaths 1 min after the postural change, and the results were compared to the values measured on a corresponding number of breaths in the control horizontal position.

A two-tailed $t$ test was used to determine if a significant difference $(P<0.01)$ existed between the two groups of values.

\section{RESULTS}

\section{IMMEDIATE EFFECTS OF THE HEAD-UP POSITION ON BREATHING

$$
\text { RATE }
$$

The changes in body posture from the horizontal position to the head-up position $\left(+45^{\circ}\right.$ and $\left.+90^{\circ}\right)$ caused an immediate decrease in breathing rate that was particularly evident in newborn rabbits and dogs (Fig. 1, top). In some instances, the tilting resulted in a short apnea period which in one case was as long as $14 \mathrm{sec}$.
The percentage drop of breathing frequency relative to the horizontal pretilt value is presented in Table 1 (left columns). It can be seen that as an immediate effect of the head-up postural change breathing rate dropped between 35 and $91 \%$ of the horizontal value. The most evident drop occurred in puppies with $+90^{\circ}$ position $(35 \% \pm 5)$; the lowest drop occurred in rats in the $+45^{\circ}$ posture $(91 \% \pm 10)$

After bilateral vagotomy, no effects on respiratory rate occurred as a result of postural changes (Fig. 1, bottom).

\section{STEADY-STATE EFFECTS ON BREATHING RATE OF THE POSTURAL CHANGES}

After the immediate drop occurring with the head-up position, breathing rate increases again (Fig. 1, top). The kinetics of this increase varies between animals; a steady-state level is in general achieved within $1 \mathrm{~min}$. The steady-state values obtained in the three species are summarized in Table 1 (right columns). No significant differences ever occurred between horizontal postures (supine, left and right lateral, and prone); therefore, the values pertaining to these positions have been grouped together, and the frequencies measured at +45 and $+90^{\circ}$ have been computed as percentage of the horizontal value $(100 \%)$. In the $+45^{\circ}$ position, respiratory rate decreased in all the puppies (down to $66 \% \pm 2$ S.D. of the horizontal value), whereas it dropped significantly in only seven of nine rabbits and in one of six rats. In the vertical head-up position $\left(+90^{\circ}\right)$, breathing rate showed a significant reduction in all the newborns, to $86 \%( \pm 8$ S.D.) of the horizontal value in rats, $83 \%( \pm 13$ S.D.) in rabbits and $43 \%$ ( \pm 29 S.D.) in dogs. In the head-down position $\left(-90^{\circ}\right)$ only two of nine newborn rabbits showed a significant increase in respiratory frequency. No

Table 1. Anesthetized newborns. Transient and steady-state effects of the +45 and $+90^{\circ}$ head-up tilting on breathing rate

\begin{tabular}{lcccccc}
\hline & & \multicolumn{2}{c}{ Transient } & & \multicolumn{2}{c}{ Steady state } \\
\cline { 3 - 4 } \cline { 6 - 7 } & $\begin{array}{c}\text { No. of } \\
\text { animals }\end{array}$ & $+45^{\circ}$ & $+90^{\circ}$ & & $+45^{\circ}$ & $+90^{\circ}$ \\
\hline Rats & 6 & $91 \pm 10^{2}$ & $75 \pm 11$ & & $96 \pm 8$ & $86 \pm 8$ \\
Rabbits & 9 & $67 \pm 24$ & $61 \pm 25$ & & $86 \pm 8$ & $86 \pm 13$ \\
Dogs & 8 & $81 \pm 19$ & $35 \pm 5$ & & $66 \pm 2$ & $43 \pm 29$ \\
\hline
\end{tabular}

${ }^{1}$ Values are expressed in percentage of pretilt values.

${ }^{2}$ Mean \pm S.D.
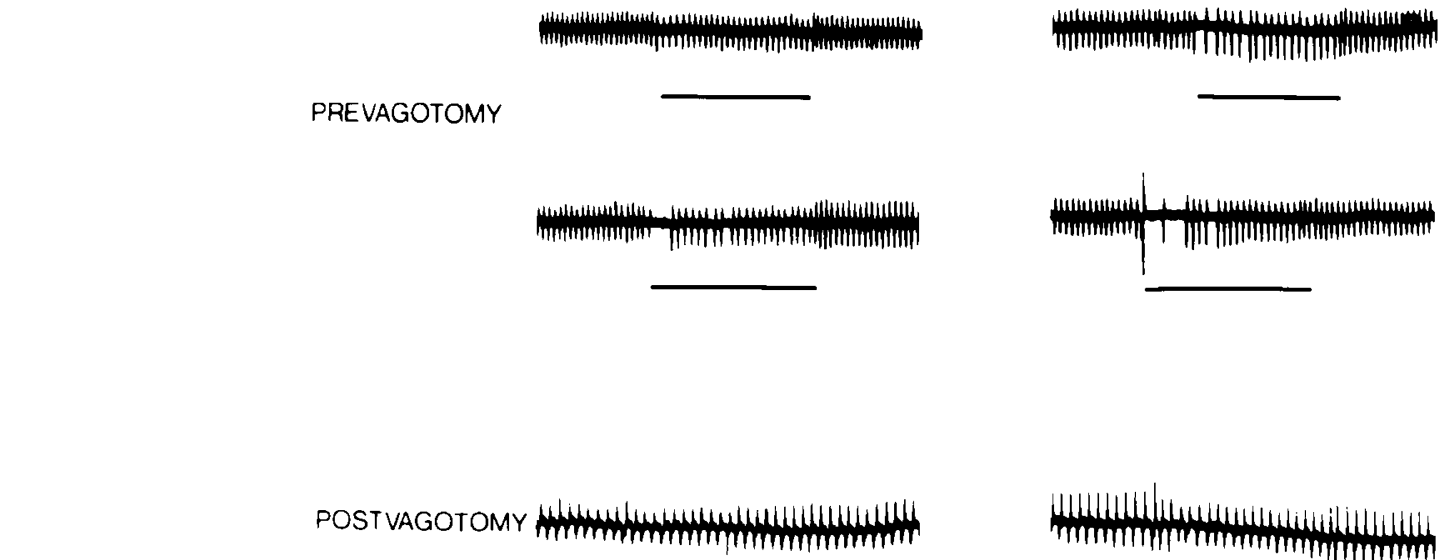

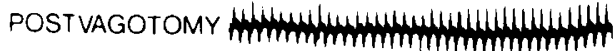

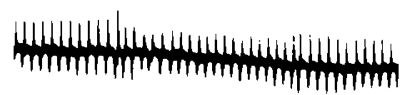

$1 \mathrm{~m}, \mathrm{n}$

Fig. 1. Records of tracheal pressure in anesthetized newborn rabbits in horizontal posture and with the +45 and $+90^{\circ}$ head-up positions maintained for the period indicated by the horizontal bars. Top and bottom records of the prevagotomy situation pertain to two different rabbits. These examples show the short period of apnea which occurs as the immediate result of the tilting and the absence of postural changes after vagotomy. 


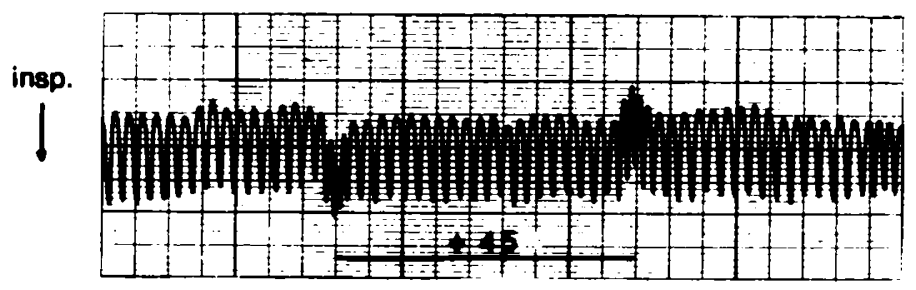

$10 \mathrm{sec}$

Fig. 2. Low-speed spirometric record of an unanesthetized newborn rabbit in horizontal postures and in $+45^{\circ}$ head-up position maintained for the periodindicated by the horizontal bar. Inspiration downward.

Table 2. Effect of $+45^{\circ}$ head-up tilting on breathing rate; sI

\begin{tabular}{clllll}
\hline & \multicolumn{2}{l}{ Unanesthetized } & \multicolumn{2}{l}{ Anesthetized } \\
\hline Puppy & & & & \\
& 1 & 86 & $(s)^{2}$ & 66 & $(s)$ \\
& 2 & 82 & $(s)$ & 66 & $(s)$ \\
& Total & $84( \pm 3)^{3}$ & & $66( \pm 0)$ & \\
Rabbit & & & & \\
& 1 & 115 & & & \\
& 94 & & 75 & $(s)$ \\
3 & 116 & & 86 & $(\mathrm{~s})$ \\
4 & 81 & $(\mathrm{~s})$ & 94 & $(\mathrm{~s})$ \\
5 & 108 & & 84 & $(\mathrm{~s})$ \\
6 & 81 & $(\mathrm{~s})$ & 80 & $(\mathrm{~s})$ \\
7 & 98 & & 79 & $(\mathrm{~s})$ \\
8 & 78 & $(\mathrm{~s})$ & & \\
9 & 93 & & & \\
Total & $96( \pm 15)$ & & $83( \pm 7)$ \\
\hline
\end{tabular}

${ }^{1}$ Values are expressed in percentage of pretilt values.

${ }^{2}(\mathrm{~s})$, significant change in breathing rate $(P<0.01)$.

${ }^{3}$ Mean \pm S.D. significant changes occurred in the other seven newborn rabbits nor in newborn rats and dogs.

After bilateral vagotomy, breathing rate in rats, rabbits, and dogs was, respectively, $46 \%$ ( \pm 19 S.D.), $56 \%$ ( \pm 5 S.D.) and $26 \%$ (+7 S.D.) of the value measured in the horizontal intact animal and did not show any significant variation with body posture (Fig. 1, bottom).

In 11 animals (two puppies and nine newborn rabbits), the effects of the $+45^{\circ}$ head-up tilting was tested before anesthesia, and an actual record pertaining to one of these rabbits is shown in Fig. 2. In two puppies and six rabbits, measurements were repeated after anesthesia; individual and mean results are presented in Table 2. Before anesthesia in the two puppies, a significant drop of breathing rate was observed (mean, $84 \pm 3$ S.D.). This was also the case of three of nine rabbits, with a mean drop to $80 \%$ ( \pm 2 S.D.), whereas no significant changes occurred in the others. All the animals studied after anesthesia had a significant drop in breathing frequency (mean of the horizontal value, $66 \%$ \pm 0 S.D. in puppies and $83 \% \pm 7$ S.D. in rabbits) and this drop was generally more marked than before anesthesia.

In the two puppies studied in unanesthetized conditions, the drop in breathing rate with tilting was due to a prolongation of the expiratory time. The inspiratory time decreased in both animals to 95 and $78 \%$ of the horizontal value but only in the second case was the decrease significant (Fig. 3, left panel). After anesthesia, the expiratory time was prolonged with the tilting, and the inspiratory time did not change (Fig. 3, right panel). Similar results were obtained in four newborn anesthetized rats where the same analysis was carried out.

\section{DISCUSSION}

A decrease in breathing rate was seen in most of the animals during the $+45^{\circ}$ head-up tilting and in all the animals with the $+90^{\circ}$ position. The reduced breathing rate was preceded in some instances by a short period of apnea. These orthostatic respiratory responses are mediated by the vagi nerves inasmuch as vagotomy abolishes the reflex, and their origin is very likely the increase in lung volume which accompanies the head-up tilting similar to that shown in adults $(10,19,20)$.
UNANESTHETIZED

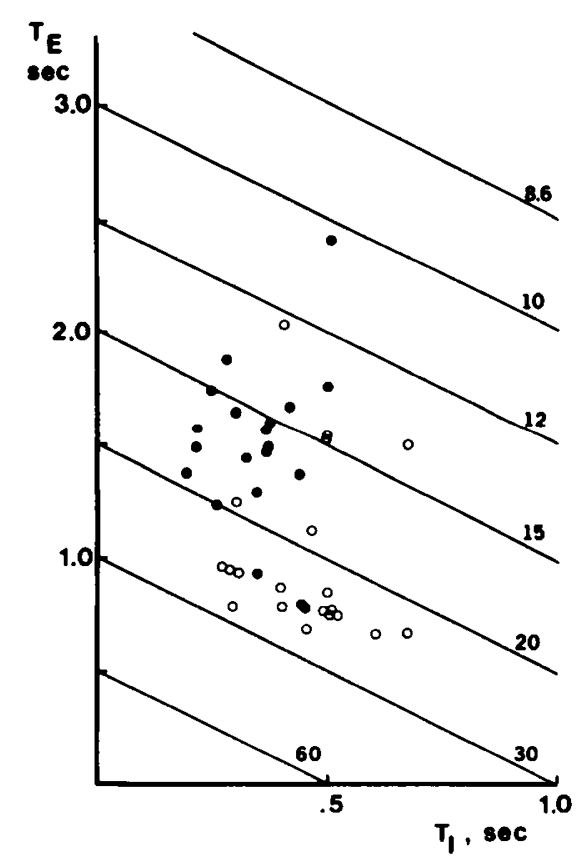

ANESTHETIZED

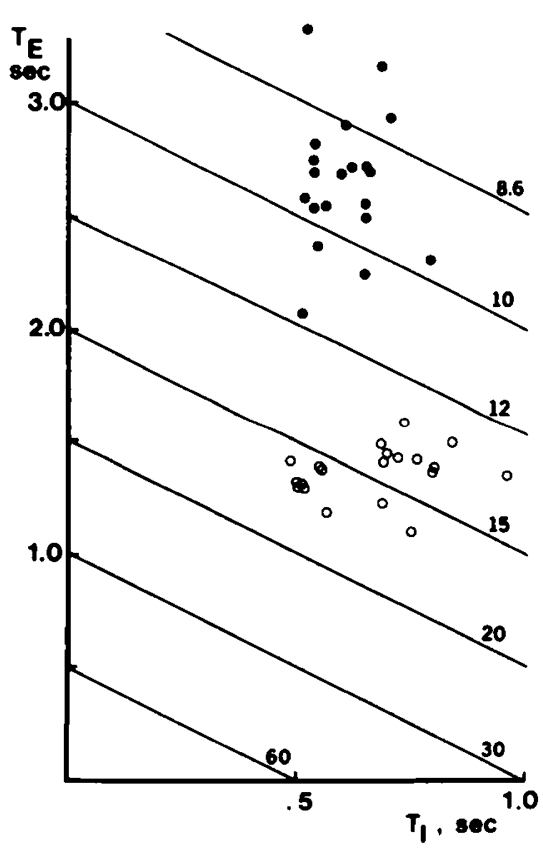

Fig. 3. Newborn puppy. Abscissa, inspiratory time $\left(\mathrm{T}_{\mathrm{I}}, \mathrm{sec}\right)$; ordinate, expiratory time $\left(\mathrm{T}_{\mathrm{E}}, \mathrm{sec}\right)$ relationship of 20 breaths in horizontal position $(\mathrm{O})$ and 20 breaths in $+45^{\circ}$ head-up posture $(\Theta)$. Left, before anesthesia; right, after anesthesia. ——, isofrequency lines. 

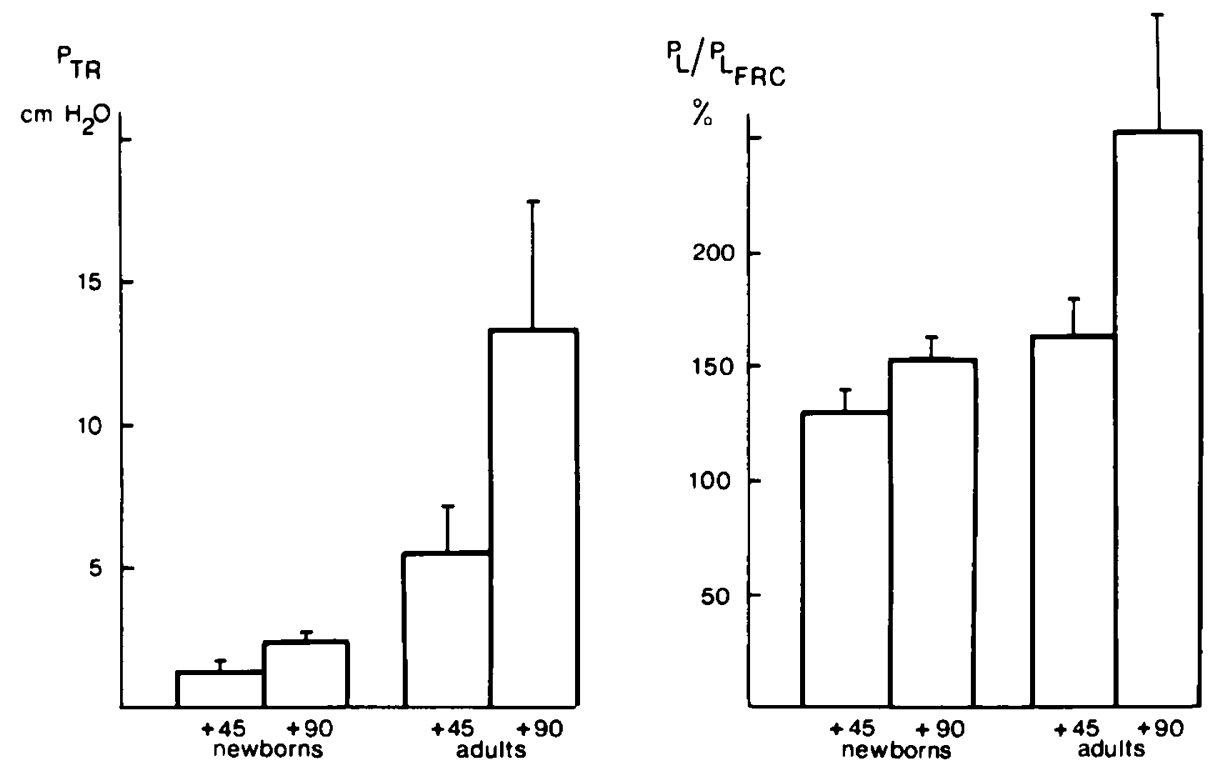

Fig. 4. Left, tracheal pressure $\left(P_{T R}, \mathrm{~cm} \mathrm{H} \mathrm{H}_{2} \mathrm{O}\right)$ measured after the +45 or $+90^{\circ}$ head-up tiltings in three newborn and three adult rabbits having the airways closed at FRC in supine posture. Columns, mean values; bars, S.D. Right, transpulmonary pressure $\left(P_{L}\right)$ expressed in percentage of the pressure measured at FRC ( $\left.P_{L_{F R C}}\right)$ for the $P_{T K}$ values presented in the left panel. $P_{L} / P_{L_{F R C}}$, has been computed on the basis of the pressure-volume curves of newborn and adult rabbits reported by Fisher and Mortola (9).

By comparing the data reported in adults $(10,14,15,20)$ with our data in newborns, it appears that both the immediate and steady-state effects of the tilting are substantially less in the newborn than in the adult. Even smaller degrees of tilting than the ones tested in this study in anesthetized adult rabbits can stop breathing for as long as 1 to $2 \mathrm{~min}$, and when ventilation resumes it is so low that respiratory insufficiency occurs $(10,20)$. In adult dogs, the head-up tilting determines an apnea of 26 to $54 \mathrm{sec}$ according to the degree of tilting $(14,15)$. In our newborns, the apnea after the tilting is not a constant finding, and when it occurs, it is usually short lasting. Furthermore, the same authors $(10,14$, $15,20)$ reported a substantial increase in breathing rate with the vertical head-down position, whereas only in two newborn rabbits we observed a significant increase.

The pressure applied to the respiratory system by the descent of the abdominal viscera is the cause of the inflation of the lung after the head-up tilting. The actual inflating pressure of the respiratory system can be estimated by halving the values of tracheal pressure obtained by tilting the animal with the airways closed at functional residual capacity (FRC) and therefore without lung expansion because the pressure across the respiratory system at FRC in supine position is zero. We have found that the tracheal pressures generated by tilting the animals after having occluded the airways at FRC were 4.5 times greater in the adult than in the newborn (Fig. 4, left panel). ${ }^{1}$ From these computations, on the basis of data of lung compliance in newborn and adult rabbits and the corresponding values of transpulmonary pressure at FRC (9), it is possible to calculate the relative change of transpulmonary pressure occurring with tilting (Fig. 4, right panel). These figures are of interest because the activity of pulmonary stretch receptors, which is responsible for the reflex lowering in breathing rate with lung expansion, is better represented by the relative changes in transpulmonary pressure than by changes in lung volume $(3,18)$. If this computation is correct, it would appear that the mechanical effect of the $+45^{\circ}$ head-up tilting in the adult is similar to that of the $+90^{\circ}$ in the newborn, even though their reflex effects are different, being more marked in the adult. Therefore, it would seem that the mechanical factors do not fully explain the difference in the response of breathing rate to tilting between newborns and adults. Different levels of anesthesia or differences in the sensitiv-

'These measurements were done in dead animals or during the "primary apnea" of asphyxia (13) which follows the period of inspiratory efforts, when the animals are still alive but respiratory efforts do not occur. ity to anesthesia, play a relevant role in the Hering-Breuer inflation reflex (4). However, in adult unanesthetized rabbits substantial orthostatic bradypnea is the common finding $(10,20)$, whereas in our newborns, the head-up tilting causes small and inconsistent effects. Even if the comparison of unanesthetized animals can be complicated by differences in the state of arousal, it seems that the effect of anesthesia is an unlikely explanation for the different postural respiratory response of newborns and adults. The absence of the reflex after vagotomy seems to rule out the contribution of chest wall or any other extravagal afferents. The response to $\mathrm{CO}_{2}$ has been reported to be either similar (2) or smaller in the newborn $(11,23,26)$; it is possible. however, that the time course of the chemical stimulus is greater in the newborn than in the adult due to its higher metabolism. This latter factor could therefore participate in explaining the different postural effect on breathing rate between newborns and adults. Finally, differences in the vagal input or in the reflex elaboration of the vagal afferents cannot be overlooked. Several studies have shown that pulmonary vagal reflexes are already developed at birth $(6,8,16,21,22,25)$. However, reflexes are often examined on the basis of changes in lung volume, which cannot be considered an adequate representation of the stimulus of pulmonary stretch receptors $(3,19)$; therefore, it cannot be excluded that reflexes depending upon tonic vagal activity are weaker in newborns than in adults when compared on the basis of the relative changes in transpulmonary pressure. Furthermore, in newborn kittens (25) and in newborn lambs (22) much less pulmonary receptor activity has been found than usually reported in adult animals.

In conclusion, the effect of postural changes on breathing rate is less evident in the newborn than in the adult in both anesthetized and unanesthetized conditions, even though the reflex pathway is the same. The quantitative difference in the mechanical events after the change in body posture between newborns and adults does not exclude the possibility that other mechanisms are involved in the explanation of the lower sensitivity of the newborn.

\section{REFERENCES AND NOTES}

1. Agostoni, E.: Volume-pressure relationships of the thorax and lung in the newborn. J. Appl. Physiol., 14: 909 (1959).

2. Avery, M. M., Chernick, V., Dutton, R. E., and Permutt, S.: Ventilatory response to inspired carbon dioxide in infants and adults. J. Appl. Physiol., 18: 895 (1963). 
3. Bartlett, D., Sant'Ambrogio, G., and Wise. J. C.: Transduction properties of tracheal stretch receptor. J. Physiol. (Lond.), 258: 421 (1976).

4. Bouverot, P., Crance. J. P., and Dejours, P.: Factors influencing the intensity of the Hering-Breuer inspiration-inhibiting reflex. Respir. Physiol., 8: 376 (1970)

5. Conklin, R. E.: Circulatory and respiratory reflexes in the rabbit during tilting Am. Rev. Tuberc. Pulm. Dis., 73: 661 (1956).

6. Cross, K. W., Klaus, M. Tooley, W. K., and Weisser, K.: The response of the newborn baby to inflation of the lungs. J. Physiol. (Lond.). 15l: 551 (1960).

7. Dahl, M., and Valimaki, I.: Postural effect on respiratory and heart rate of newborn infants. An impedance pneumographic study. Biol. Neonate, 20: 161 (1972).

8. Dawes, G. S., and Mott, J. C.: Reflex respiratory activity in the newborn rabbit. J. Physiol. (Lond.), 45: 85 (1959).

9. Fisher, J. T., and Mortola, J. P.: Statics of the respiratory system in newborn mammals. Respir. Physiol., 41: 155 (1980)

10. Gordh, T.: Postural circulatory and respiratory changes during ether and intravenous anesthesia. Acta. Chir. Scand., 92: 1 (1945).

11. Krauss, A. N., Klain, D. B., Waldman, S., and Auld, P. A.: Ventilatory response to carbon dioxide in newborn infants. Pediatr. Res., 9: 46 (1975).

12. Kravitz, H., Elegant, L., Block, B., Babakitis, M., and Lundeen, E.: The effect of position on the respiratory rate of premature and mature newborn infants. Pediatrics, 22: 432 (1958).

13. Lawson. E. A., and Thach. B. T.: Respiratory patterns during progressive asphyxia in newborn rabbits. J. App. Physiol., 43: 468 (1977).

14. Liu, C. T., Hoff, M. E., and Huggins, R. A.: Circulatory and respiratory responses to postural changes in the hemorrhagic dog. J. Appl. Physiol., 27: 460 (1969).

15. Liu, C. T., Huggins, R. A., and Hoff, H. E.: Circulatory and respiratory responses to postural changes in the vagotomized dog. Aerosp. Med., 41: 654 (1970).

16. Martin, R. J., Okken, A., Katona, P. G., and Klaus, M. K.: Effect of lung volume on expiratory time in the newborn infant. J. App. Physiol., 45: 18 (1978).

17. Mead, J. N., Peterson, N., Grimby, G., and Mead, J.: Pulmonary ventilation measured from body surface movements. Science (Wash. D. C.). 3: 1383 (1967).

Copyright (C) 1980 International Pediatric Research Foundation, Inc.

$0031-3998 / 80 / 1412-1403 \$ 2.00 / 0$
18. Mortola, J. P., and Mortola, S.: Tracheal slowly adapting stretch receptors: theoretical models. J. Theor. Biol., 83: 313 (1980).

19. Mortola, J. P., and Sant'Ambrogio, G.: Reflex responses of respiratory muscles to tilting and positive pressure breathing. Arch. Fisiol., 70: (1973)

20. Moruzzi, G.: Sul meccamismo delle modificazioni posturali del respiro. Arch. Sci. Biol., 30: 221 (1945).

21. Olinsky, A., Bryan. M. H., and Bryan, A. C.; Influence of lung inflation on respiratory control in neonates. J. Appl. Physiol., 36: 426 (1974).

22. Ponte, J., and Purves, M. J.: Types of afferent nervous activity which may be measured in the vagus nerve of the sheep foetus. J. Physiol. (Lond.), 229: 51 (1973).

23. Rigatto, H.. Brady, J., and de la Torre Verduzco, R.: Chemoreceptor reflexes in preterm infants: the effect of gestational postnatal age on the ventilatory response to inhaled carbon dioxide. Pediatrics, 55: 614 (1975).

24. Salathè, A.: De l'anemie et de la congestion cérébrales provoquées mécaniquement chex les animaux par l'attitude verticale ou par un movement giratoire. Trav. Lab. Marey, 3: 261 (1877).

25. Schwieler, G. H.: Respiratory regulation during postnatal development in cats and rabbits and some of its morphological substrate. Acta Physiol. Scand. Suppl., 304: 1 (1968).

26. Woodrum, D. E., Guthrie, R. D., and Hodson, W. A.: Development of respiratory control mechanisms in the fetus and newborn. In: W. A. Hodson: Development of Lung Pp. 561-585 (New York, 1977).

27. Wyszogrodski, I., Thach, B. T., and Milic-Emili, J.: Maturation of respiratory control in unanaesthetized newborn rabbits. J. Appl. Physiol., 44: 304 (1978).

28. Requests for reprints should be addressed to: Jacopo P. Mortola. Department of Physiology, 3655 Drummond Street, McGill University, Montreal, Quebec, Canada H3G IY6.

29. This research was supported by Candian MRC Grant $248-42$ and Hospital for Sick Children Foundation. Toronto, Canada.

30. Received for publication January 29, 1980.

31. Accepted for publication May 9, 1980 